\title{
ОПАСНЫЕ ПРИРОДНЫЕ ПРОЦЕССЫ - ГЛОБАЛЬНАЯ УГРОЗА СОВРЕМЕННОСТИ
}

\author{
Кузьмин С. Б.
}

В статье рассмотрены стихийнье бедствия и природные катастрофы как глобальная угроза современной цивилизаџии. В последнее время негативное влияние природных прочессов на население и экономику планеты многократно увеличилось, проявляется практически во всех регионах Земли, наносит колоссальный ущерб всем хозяйственным отраслям, приводит к массовой гибели людей. Причины этого двоякие. Во-первых, это собственно развитие общества и мировой экономики, стремительный в последние годы рост численности населения Земли, особенно городского, беспрецедентное загрязнение окружающей среды и антропогенная активизация опасных природных процессов, изъятие невозобновляемых или длительно возобновляемых природных ресурсов. Во-вторых, это резкие естественные изменения климата и природной среды, рост среднегодовой температуры воздуха, изменение циркулячии воздушных масс и океанических течений, с чем связаны таяние ледников и деградация вечной мерзлоты на континентах, увеличение водности рек, засухи и опустынивание земель, затопление прибрежных районов морей и т. п. Рост числа и масштабов стихийных бедствий заставляют правительства стран все чаще вводить режим чрезвычайных ситуачий природного и природно-техногенного характера, тратить огромные средства на восстановление разрушенной экономики и территорий, реабилитацию жителей. Исследования последних лет показывают, что в связи с этим на первый план сегодня выходят превентивные меры борьбы с опасными природными прочессами и явлениями. Превентивный подход требует от структур управления расширения сферы надзора, мониторинга и контроля риска природопользования. Это, несомненно, обостряет полемику вокруг стратегий оченки и реагирования на риски. В ичелом риск-ориентированный подход становится сегодня основой государственной политики в области защиты от стихийных бедствий и природных катастроф во многих развитых странах мира, в том числе и в Российской Федеращии.

Ключевые слова: опасные природные прочессы, стихийныле бедствия, риск природопользования, безопасность населения и экономики, мониторинг.

Natural disasters are considered as a global threat to modern civilization. Recently, the negative impact of natural processes on the population and economy of the planet has increased many times, and manifests itself in almost all regions of the Earth, it causes colossal damage to all economic sectors and leads to mass death of people. The reasons for this are twofold. First, it is the development of so-

\footnotetext{
${ }^{*}$ Кузьмин Сергей Борисович - д. геогр. н., в. н. с. Института географии им. В. Б. Сочавы Сибирского отделения Российской Академии наук. E-mail: sbkuzminhome@yandex.ru.
}

Век глобализации 2/2021 17-29 
ciety and the world economy itself, the rapid growth of the world's population in recent years, especially urban, unprecedented environmental pollution and anthropogenic activation of dangerous natural processes, the withdrawal of nonrenewable or long-term renewable natural resources. Secondly, these are abrupt natural changes in climate and the natural environment, an increase in the average annual air temperature, a change in the circulation of air masses and ocean currents, which is associated with the melting of glaciers and the degradation of permafrost on the continents, an increase in the water content of rivers, droughts and desertification of lands, flooding of coastal areas seas, etc. The increase in the number and scale of natural disasters is forcing the governments of countries more and more often to establish emergencies of a natural and natural-man-made nature, to spend huge amounts of money on the restoration of the destroyed economy and territories, and the rehabilitation of citizens. Recent studies show that in this regard, preventive measures to combat hazardous natural processes come to the fore today. The preventive approach requires from the management structures to expand the scope of supervision, monitoring and control of environmental risks. This undoubtedly exacerbates the controversy over risk assessment and response strategies. In general, the risk-based approach is now becoming the basis of state policy in the field of protection against natural disasters in many developed countries of the world, including the Russian Federation.

Keywords: hazardous natural processes, natural disasters, risk of nature management, safety of the population and economy, monitoring.

\section{Введение}

В докладе Всемирного экономического форума 2020 г. в Давосе сказано, что восприятие глобального риска общественного развития существенно меняется в последнее время. Если в предыдущие годы экономические проблемы считались самой большой угрозой для человечества, то сейчас впервые все главные долгосрочные риски развития являются экологическими. Восприятие рисков специалистами переместилось на экстремальные погодные условия, стихийные бедствия и природные катастрофы, включая деградацию окружающей природной среды, распространение природно-очаговых инфекций (например, коронавируса), утрату био- и георазнообразия ландшафтов, неспособность смягчить негативное влияние на цивилизацию современных темпов изменения климата. Тесное сотрудничество между мировыми лидерами и политиками, бизнесменами, предприятиями и организациями является на текущем этапе развития общества необходимым для предотвращения самых серьезных угроз окружающей среде, здравоохранению и технологическим системам.

И, как показывает практика последних лет, главную угрозу сегодня представляют опасные природные процессы и явления: 1) геофизические, прежде всего землетрясения и вулканизм; 2) геологические, главным образом - оползни, обвалы, эрозия почв, карстовые провалы и др.; 3) метеорологические, такие как ураганы, шквалы, смерчи, торнадо, аномально жаркая погода, пыльные бури и др.; 4) агрометеорологические, губительные для сельского хозяйства - заморозки, засухи, суховеи и др.; 5) гидрологические, такие как наводнения, зажоры, заторы, сходы снежных лавин, сели и др.; 6) морские гидрометеорологические - цунами, 
штормы, интенсивный дрейф льдов, обледенение судов, отрыв прибрежных льдов с людьми на внутренних и внешних водоемах и др.; 7) природные лесные и торфяные пожары; 8) природно-очаговые инфекции, эпидемии; 9) природно-антропогенные, такие как подтопление территорий в городах, просадки грунтов, наведенная сейсмичность и др.

При решении глобальных проблем, связанных со стихийными бедствиями, риск наших действий всегда будет являться основной проблемой. Подходы и методы его анализа используются сегодня уже достаточно широко как учеными, так и практиками, но анализ риска не является общепринятой наукой. Ключевой проблемой здесь являются отсутствие объяснительной силы и большая неопределенность при оценке риска. Область применения риска не рассматривается в соответствии с основополагающими научными критериями и принципами, так как требуется, чтобы они содержали правдивые утверждения о мире и некоторые объективные решения. А сама природа риска такова, что он как раз и оперирует прежде всего с понятиями неопределенности и непредсказуемости. Но именно анализ риска позволил перейти к фундаментальному изменению мышления исследователей и политиков, от поиска точных прогнозов и оценок развития общества к генерации знаний, связанных с концепциями, теориями, принципами, подходами, методами и моделями [Aven 2018].

\section{Стихийные бедствия и природные катастрофы}

Сегодня практически во всех странах и регионах наблюдается стремительный рост числа и масштабов стихийных бедствий и природных катастроф, материального и морального ущерба от них вне зависимости от предпринимаемых беспрецедентных мер защиты, главным образом в высокоразвитых государствах. И особенно страдают от опасных природных процессов слаборазвитые государства. Все чаще в разных странах мира правительства вынуждены объявлять чрезвычайные ситуации природного и природно-техногенного характера. По данным Мюнхенской компании перестрахования Munich Re $e^{1}$, за период с 1980 по 2020 г. наибольшее количество стихийных бедствий на планете приходилось на метеорологические - 44,4 \%, гидрологические - 21,8 \%, геофизические - 19,7 \%, климатологические $-14,1$ \%. При этом средняя температура воздуха на Земле, начиная с 1880 г., в течение 140 лет с переменным знаком, но устойчиво растет, особенно в последние 40 лет.

\footnotetext{
${ }^{1}$ Мюнхенская компания перестрахования Munich Re со штаб-квартирой в Германии обслуживает более 60 филиалов перестрахования, отделений, сервисных компаний и компанийпосредников во всем мире. Ее деловыми партнерами являются 5 тысяч страховых фирм в более чем 160 странах. Эти компании передают Munich Re часть ответственности по возмещению рисков, которую они страхуют. Отдел исследований географических рисков Munich Re в течение 40 лет собирает и анализирует информацию о природных опасностях и катастрофах во всем мире. Эта информация включает место инцидента, его дату и продолжительность, описание повреждений или разрушений зданий, воздействие на инфраструктуру, повреждение инженерных сетей, сельскохозяйственных угодий и т. п. Кроме того, в базу данных заносятся сведения о воздействии на население, включая число погибших, раненых, оставшихся без крова и пропавших без вести. Наконец, фиксируется размер экономического ущерба и страховых потерь.
} 
По данным Всемирной метеорологической организации, зимний сезон 20192020 гг. принес самые экстремальные показатели по изменению климата: 1) ни в одной точке планеты в январе 2020 г. не было отрицательных температурных аномалий; 2) на пять лет - 2016-2020 гг. - приходится четыре самых теплых января за всю историю метеонаблюдений; 3) в феврале 2020 г. в Антарктиде температура воздуха превысила $+20{ }^{\circ} \mathrm{C}$, что также происходит впервые; 4) Австралия в 2019 г. стала одновременно самым жарким и самым сухим континентом, масштабность лесных пожаров не предсказывал даже самый пессимистичный прогноз, катаклизмы подобного рода ожидались лишь к 2050 г.

Существует три главных причины глобального роста активности и масштабности стихийных бедствий и природных катастроф, материального ущерба от них, числа погибших и пострадавших среди населения: 1) рост численности населения Земли, особенно городского (урбанизация), масштабов, интенсивности и энергоемкости глобальной экономики, включая потребление невозобновимых природных ресурсов; 2) глобальная деградация природной среды, сокращение площади регионов, благоприятных для проживания человека, потеря ими ресурсного потенциала; 3) глобальные изменения природной среды и климата, в том числе связанные с антропогенным фактором, - выбросы вредных веществ в атмосферу, вырубка лесов, деградация почв, опустынивание и др. С ними связано множество более мелких причин, которые сегодня активно обсуждаются в отечественной и мировой литературе [O’Neill et al. 2006; Richardson et al. 2011; Кобышева и др. 2015; Синяк 2016; Tong et al. 2016; Яковлева и др. 2018; Benegal 2018; Leng 2018; Tigchelaar et al. 2018 и др.]. Более того, этот процесс усугубляется недостаточным взаимодействием (а часто - полным его отсутствием) между людьми, профессионально изучающими опасные природные процессы, учеными и людьми, принимающими решения по управлению социально-экономическими институтами общества, а также несущими ответственность за предупреждение, ликвидацию и смягчение последствий чрезвычайных ситуаций природного и природно-техногенного характера.

\section{Глобальный ущерб от опасных природных процессов}

С 1980 по 2018 г. ущерб для мировой экономики в связи со стихийными бедствиями и природными катастрофами составил более 5,6 трлн долларов. Основная доля этих экономических убытков - около 4 трлн долларов - не была застрахована и легла на плечи правительств. Опасность природных процессов и экономический риск для таких стихийных бедствий не рассчитывались. Причем распределение количества незастрахованных стихийных бедствий за этот период имеет следующий вид: метеорологические - 71,2 \%, климатологические - $10 \%$, геофизические - 9,4 \%, гидрологические - 9,4 \% [Holzheu, Turner 2018]. По данным $\mathrm{OOH}$ и страхового брокера $A$ on $P L C^{2}$, рост угрозы со стороны опасных при-

${ }^{2}$ Aon PLC- англо-американская компания, созданная в 1982 г. в Лондоне, ныне с главной штаб-квартирой в Ирландии - является мировым лидером в области риск-менеджмента, брокерских услуг по страхованию и перестрахованию, консалтингу по управлению персоналом. Более 65000 сотрудников Aon PLC в 120 странах мира в 500 офисах предлагают клиентам эффективные и инновационные решения в области риск-менеджмента, в том числе в части страхования и перестрахования от стихийных бедствий и природных катастроф. 
родных процессов в последние десятилетия очевиден. Так, за период 20002019 гг. произошло 7348 глобальных природных катаклизмов, которые унесли жизни более 1,23 млн человек. В результате этих катастроф мировая экономика потеряла около 4,17 трлн долларов (1,19 трлн - в период с 2000 по 2009 г. и около 2,98 трлн - в период с 2010 по 2019 г.). В то время как за предыдущие 20 лет, с 1980 по 1999 г., было зафиксировано почти в два раза меньше природных катастроф - 4212. Хотя они унесли также достаточно много жизней, свыше 1,19 млн человек, но мировая экономика потеряла лишь 1,63 трлн долларов.

В международной практике риск-менеджмента для оценки и анализа негативного влияния стихийных бедствий и природных катастроф на социально-экономическую сферу оперируют понятием потери, различая при этом прямые и косвенные потери. К прямым относятся непосредственные эффекты разрушительного воздействия на субъекты производства товаров и услуг (предприятия, организации, в том числе финансово-кредитной сферы), цена которых устанавливается рынком. Для этих субъектов последствия негативного воздействия опасных природных процессов реализуются в виде утраты их активов - полной или частичной утраты основных фондов и произведенной продукции. Такой вид прямых потерь нередко именуется рыночными потерями. Они оцениваются как стоимость замены, ремонта или восстановления утраченного или поврежденного имущества, которая определяется как разница между исходной рыночной ценой активов (или их страховой ценой, если объект был застрахован) и ценой утраты, рассчитываемой путем инвентаризации или моделирования нанесенного им физического ущерба. Кроме того, к прямым потерям относят такие последствия разрушительного воздействия опасных природных процессов, которые не могут быть смягчены или преодолены путем приобретения необходимых товаров и услуг на рынке. Этот вид прямых потерь квалифицируется как нерыночные потери и включает гибель и травмы людей, разрушение экосистем, объектов культурного наследия и т. п. Иногда используют квазирыночные денежные оценки, например, ценность среднестатистической человеческой жизни, но относительно этих оценок нет единой точки зрения.

К косвенным относят все виды потерь, которые обусловлены не самим разрушительным воздействием опасного природного процесса, а его последствиями, прежде всего нарушением технологических, производственных и в целом бизнеспроцессов. Обычно происходит массовое сокращение выпуска товаров и услуг, что расширяет социальные и географические границы бедствия, увеличивает продолжительность негативного воздействия на экономику. Неслучайно косвенные потери иногда именуются потерями второго порядка, или потерями выпуска, под которыми понимается стоимость урона хозяйствующим субъектам, в первую очередь бизнесу, от нарушения непрерывности и устойчивости производственнотехнологических и логистических цепочек и циклов. Для бизнеса такого рода урон - не что иное, как упущенный доход или выгода. Косвенные потери, как и прямые, могут быть рыночными и нерыночными [Pelling et al. 2002; Rose 2004; Hallegatte, Przyluski 2010].

В Российской Федерации обычно оперируют понятием ущерб. Прямой ущерб включает: 1) ущерб основным фондам (производственным активам, в том числе 
складским запасам и т. п.), сырьевым и извлекаемым природным ресурсам; 2) ущерб здоровью человека в виде роста смертности и заболеваемости как непосредственное следствие стихийного бедствия. Прямой ущерб имеет четкие временные и пространственные границы, привязанные к месту и моменту разрушительного воздействия конкретного стихийного бедствия.

Косвенный ущерб от стихийных бедствий включает полное или частичное разрушение экосистем, объектов культурно-исторического наследия, памятников природы и т. п. Обычно такой ущерб оценивается как сокращение или утрата ожидаемых доходов от использования перечисленных объектов, которые рассчитываются через готовность потребителей, а вслед за ними - и производителей платить за сохранение или развитие этих ценностей. В отличие от прямого ущерба, он не имеет привязки к точно очерченной территории или установленному времени и включает снижение или потерю доходов от хозяйственной деятельности, которая прекращается или сокращается из-за стихийного бедствия или его последствий на территориях, в том числе находящихся на значительном удалении от зоны бедствия, а также спустя заметное время (месяцы, а иногда и годы) после возникновения чрезвычайной ситуации.

Снижение или потеря доходов предприятий и бюджетов разного уровня обычно являются следствием трех факторов: 1) прямого ущерба, например, техногенным, инфраструктурным, социальным, природным и культурным объектам, которые прекращают или сокращают предоставление услуг, и соответствующие хозяйствующие субъекты не получают вовсе или получают меньший доход; 2) переключения ресурсных потоков (прежде всего инвестиций) с производства на восстановительные работы, что снижает загрузку мощностей и выпуск продукции; 3) дополнительных издержек и сокращения выпуска продукции, обусловленных необходимостью использовать альтернативные и/или менее производительные мощности и системы распределения товаров и услуг взамен более продуктивных, которые использовались ранее, но выбыли из строя в результате стихийного бедствия [Порфирьев, Макарова 2014].

\section{Борьба со стихийными бедствиями}

Устойчивая глобальная тенденция роста ущерба от стихийных бедствий требует разработки новой стратегии борьбы с опасными природными процессами и явлениями, основанной на оценке риска природопользования для смягчения их последствий. Реализация такой стратегии позволит правительствам перейти на социально-экономическое планирование и развитие с учетом риска. Это повысит безопасность населения, экономики и территорий, сократит моральные и материальные потери в результате хозяйственной и любой иной деятельности общества в обстановке неизбежности стихийных бедствий.

Важная часть этой глобальной стратегии - разработка новых унифицированных алгоритмов, методик и процедур составления и анализа карт районирования территорий по опасным природным процессам, а на их основе прогностическая пространственная оценка риска стихийных бедствий. Такие карты позволят структурам управления территориями сопоставлять угрозы для отдельных стран, муниципалитетов, регионов. Они будут составлены с использованием их соб- 
ственных финансовых средств, научного потенциала и банков данных, что повысит ответственность представителей исполнительной власти как в национальном плане, так и на местах. Эти карты должны служить также основой для разработки нормативных документов, с учетом которых органы исполнительной власти принимают решения по использованию территорий и управлению риском природопользования. Особо важны принятие специальных законодательных решений о величине приемлемого и допустимого риска, информирование населения о природных опасностях [Осипов 2009].

В практике административно-территориального управления как в Российской Федерации, так и за рубежом основным подходом для оценки и прогнозирования опасных природных процессов, их поражающих воздействий на население, хозяйственные объекты, экосистемы и территории является статистический анализ динамических рядов данных о стихийных бедствиях для последующего построения трендовых зависимостей. Но в силу нелинейности воздействия поражающих факторов по статистическим трендовым моделям не всегда удается предсказать последствия воздействия негативных факторов и степень поражения объекта и прилегающей территории. Поэтому инструментарий, основанный на анализе статистических данных, нуждается в дополнении другими методами анализа и прогноза развития как источников чрезвычайных ситуаций природного и природнотехногенного характера, так и оценки их последствий с учетом состояния объектов экономики и инфраструктуры, систем инженерной защиты населения и территорий, например, методами специального районирования территорий по опасным природным процессам.

Возрастание угроз трансграничного характера, когда стихийному бедствию подвергаются сразу несколько стран, требует объединения усилий на международном уровне. Это влечет за собой необходимость приведения национальных систем оценки риска к единым стандартам, унификацию оценочных шкал и выбор согласованной системы индикаторов. Для оценки риска природопользования необходимо идентифицировать природные опасности, оценить уровень их воздействий и уязвимость/защищенность объектов.

При этом следует обращать особое внимание на следующие важные моменты: 1) каким образом опасные природные процессы трансформируются с течением времени под влиянием таких, например, факторов, как урбанизация и изменение климата; 2) каким образом сочетаются несколько опасностей, то есть оценить кумулятивный и каскадный эффекты повторяющихся стихийных бедствий и природных катастроф; 3) изучить триггерные механизмы, поскольку один опасный природный процесс часто инициирует другой или даже цепочку взаимосвязанных катастрофических событий; 4) изучить негативные последствия для территорий, окружающих очаги бедствия; 5) исследовать все социальные слои населения, подверженные воздействиям; 6) идентифицировать объекты экономики и виды хозяйственной деятельности, подвергающиеся воздействиям; 7) прежде всего идентифицировать критически важные инфраструктурные объекты и вытекающие из этой оценки риски каскадных отказов (например, прекращение подачи электроэнергии влечет за собой прекращение подачи воды, нарушение работы социальных объектов и др.); 8) оценить продолжительность действия поражаю- 
щих факторов опасных природных процессов, уязвимость социальных и производственных объектов, уровень воздействия и необходимость реагирования; 9) составить карты риска и воздействий с детализацией вышеуказанных моментов. Разработанные сценарии должны: 1) быть средством принятия текущих и будущих политических и инвестиционных решений; 2) регулярно обновляться; 3) широко распространяться и использоваться для корректировки планов экстренного реагирования и восстановления после бедствий [Управление... 2016; Paterson, Charles 2019].

Опыт предотвращения риска природопользования и управления им в ситуациях, обусловленных стихийными бедствиями и природными катастрофами, в высокоразвитых странах изучается сегодня в рамках дисциплины «emergency management» [Haddow, Bullock 2005]. Ее теоретические положения состоят из заблаговременной подготовки к чрезвычайной ситуации до ее наступления (планирование, подготовка, обучение населения), реагирования на кризисную ситуацию (эвакуация, карантин, химическая обработка, применение полицейских и вооруженных сил), поддержки населения и участия в восстановительных работах после стихийного бедствия. Основа отечественного и зарубежного опыта управления риском - это заблаговременное планирование самого процесса управления риском и способов его минимизации, ликвидации негативных последствий стихийных бедствий. Чрезвычайные планы в обязательном порядке периодически корректируются. Управление включает в себя: 1) определение или идентификацию рисков; 2) их оценку и ранжирование; 3) управление ресурсным обеспечением; 4) планирование ответной реакции на возникшую ситуацию и угрозу; 5) отчетность и мониторинг эффективности управления рисками; 6) анализ системы управления рисками [Бецков, Тагиров 2017].

В глобальном масштабе развитию национальных систем управления риском способствуют несколько организаций: ЮНДАК - Группа экспертов ООН по оценке последствий бедствий и координации международного реагирования (UNDAC), Международная организация гражданской обороны (The International Civil Defense Organization, ICDO), Международное общество по управлению в чрезвычайных ситуациях (The International Emergency Management Society, TIEMS), GDACS - глобальная система координации и оповещения в режиме реального времени о стихийных бедствиях и катастрофах и координации реагирования поисково-спасательных отрядов, а также в определенной мере - Международное движение Красного Креста и Красного Полумесяца, ряд других некоммерческих неправительственных организаций. Различными профессиональными организациями, такими как ASIS (Глобальное сообщество специалистов по безопасности), FEMA (Федеральное агентство США по чрезвычайному управлению), Британский колледж чрезвычайного планирования, разработаны специальные принципы планирования готовности к чрезвычайным ситуациям: 1) заблаговременное обучение персонала и населения, регулярные испытания и тестирования на знание порядка действий при стихийных бедствиях; 2) планирование и проверка работоспособности способов и средств связи; 3) профилактика чрезвычайных ситуаций, предотвращение рисков, обеспечение постоянной защиты от стихийных бедствий, поскольку угрозы здоровью и жизни могут быть снижены 
хорошо отработанными планами эвакуации, экологическим планированием и применением международных стандартов проектирования; 4) обеспечение всесторонней готовности населения к чрезвычайным ситуациям природного и природно-техногенного характера.

\section{Заключение}

За последние несколько десятилетий в мире назревали глубокие изменения в подходах к анализу риска, обусловленные ростом активности и масштабов опасных природных процессов. И сегодня произошел взрыв новых институциональных форм и стратегий, которые децентрализуют регулирование рисков и выводят на первый план метарегулирование. Уже набрал силу превентивный подход, который требует расширения сферы надзора, мониторинга и контроля риска природопользования, что обострило споры по поводу стратегий оценки и реагирования на риски. В настоящее время преобладают две точки зрения по регулированию риска для объяснения этих тенденций. Первая понимает их как отражение преобразования государства, рынка и общества в привилегию экономической свободы или объяснительную структуру, которую можно назвать неолиберальным государственным управлением. Вторая утверждает, что эти тенденции отражают практические требования простых людей, общества для более эффективного и действенного регулирования и управления рисками или пояснительную основу, которую можно назвать функциональной адаптац̧ией. Однако для наилучшего анализа и регулирования риска необходимо тесное взаимодействие между тем, как люди и общество определяют риски и опасности, и тем, как государственные структуры управления стремятся контролировать эти риски и опасности [Ansell, Baur 2018].

На всех уровнях государственного управления и контроля должно существовать четкое и однозначное представление о том, что понимать под опасными природными процессами и риском природопользования, как их следует изучать и оценивать, в чьей компетенции находятся вопросы пространственного развития территорий, подверженных стихийным бедствиям. Это позволит выработать механизмы защиты населения, экономики и территорий от негативного проявления природных процессов, снизить ущерб и предотвратить убытки. Весь процесс управления риском природопользования можно представить в виде простого алгоритма: население и экономика - природные процессы и явления - опасные природные процессы и явления - стихийные бедствия и природные катастрофы чрезвычайные ситуации природного и природно-техногенного характера - риск природопользования, начиная от их выявления, через идентификацию и анализ, до управления и контроля (см. рис. на с. 26).

Взаимодействие человека и природы происходит постоянно и на разных уровнях. Природа, природные ресурсы - это бессменный источник нашего существования. Если результаты этого взаимодействия негативные, то природные процессы и явления становятся опасными для человека, экономики и территорий. Если человек благоразумен и предусмотрителен, он старается избежать опасности. Но такая ситуация возможна далеко не всегда и по разным причинам. Если при-родной опасности все-таки не избежать, человек может выполнить ряд действий, представленных на рисунке в левой колонке. 


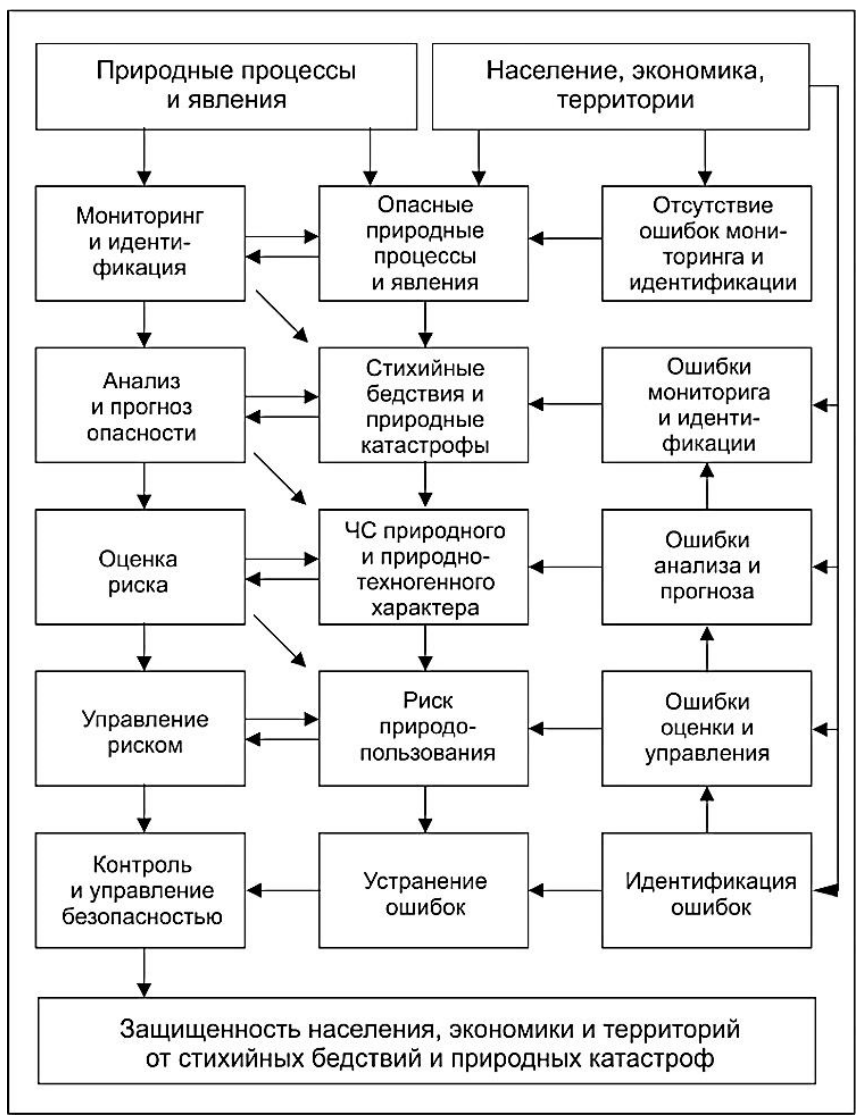

Рис. Алгоритм защищенности населения, экономики и территорий от опасных природных процессов и снижения риска природопользования

Однако он не должен допускать при этом ошибок, что позволит ему защитить себя, экономику и территории (экосистемы) от стихийных бедствий и катастроф. Но и такая ситуация - это лишь идеальная конструкция, к которой нужно стремиться. Достичь ее очень трудно, поскольку человек всегда совершает много ошибок. Ошибки при мониторинге и идентификации опасных природных процессов приводят к тому, что эти процессы перерастают в стихийные бедствия и природные катастрофы. В этом случае следует перейти уже к их анализу и прогнозу и действовать далее по алгоритму на рисунке. Ошибки при анализе и прогнозе стихийных бедствий приводят к чрезвычайным ситуациям природного и природнотехногенного характера, а ошибки при оценке и управлении чрезвычайными ситуациями - к возрастанию риска природопользования. На любом этапе алгоритма на рисунке органам управления населением, экономикой и территориями на всех уровнях всегда предоставляется определенная возможность исправить допущенные ошибки и вернуться к показанному в левой колонке на рисунке пути обеспечения безопасности вверенных им структур. 


\section{Лuтература}

Бецков А. В., Тагиров 3. И. Системы управления в чрезвычайной обстановке: международный опыт и возможности его использования в России и в государствахчленах Евразийского экономического союза // Проблемы безопасности и чрезвычайных ситуаций. 2017. № 6. С. 3-13.

Кобышева Н. В., Акентьева Е. М., Галюк Л. П. Климатические риски и адаптация к изменениям и изменчивости климата в технической сфере. СПб. : Кириллица, 2015.

Осипов В. И. Природные опасности и стратегические риски в мире и России // Экология и жизнь. 2009. № 11-12. С. 5-15.

Порфирьев Б. Н., Макарова Е. А. Экономическая оценка ущерба от природных бедствий и катастроф // Вестник РАН. 2014. Т. 84. № 12. С. 1059-1072.

Синяк Ю. В. Влияние климатических рисков на темпы и структуру развития Российского ТЭК в первой половине XXI века // Энергетическая политика. 2016. № 3. C. $31-42$.

Управление рисками техногенных катастроф и стихийных бедствий / под ред. М. И. Фалеева. М. : Изд-во ФГБУ ВНИИ ГОЧС, 2016.

Яковлева Е. Н., Яшалова Н. Н., Рубан Д. А., Васильцов В. С. Методические подходы к оценке природно-климатических рисков в целях устойчивого развития государства // Ученые записки Российского государственного гидрометеорологического университета. Раздел: Экология. 2018. Вып. 52. С. 120-137.

Ansell C., Baur P. Explaining Trends in Risk Governance: How Problem Definitions Underpin Risk Regimes // Risk, Hazards, \& Crisis in Public Policy. 2018. Vol. 9(4). Pp. 397-430.

Aven T. An Emerging New Risk Analysis Science: Foundations and Implications // Risk Analysis. 2018. Vol. 38(5). Pp. 876-888.

Benegal S. D. The Impact of Unemployment and Economic Risk Perceptions on Attitudes Towards Anthropogenic Climate Change // Journal of Environmental Studies and Sciences. 2018. Vol. 8. Pp. 300-311.

Haddow G. D., Bullock J. A. Introduction to Emergency Management. Amsterdam : Butter-Worth-Heinemann Press, 2005.

Hallegatte S., Przyluski V. The Economics of Natural Disasters: Concepts and Methods. Policy Research Working Paper No. WPS 5507. Washington, DC : World Bank Press, December, 2010.

Holzheu T., Turner G. The Natural Catastrophe Protection Gap: Measurement, Root Causes and Ways of Addressing Underinsurance for Extreme Events // The Geneva Papers on Risk and Insurance. 2018. Vol. 43(1). Pp. 37-71.

Leng G. Keeping Global Warming Within $1.5^{\circ} \mathrm{C}$ Reduces Future Risk of Yield Loss in the United States: A Probabilistic Modeling Approach // Science of the Total Environment. 2018. Vol. 644. Pp. 52-59.

O’Neill B., Ermoliev Y., Ermolieva T. Endogenous Risks and Learning in Climate Change Decision Analysis // Lecture Notes in Economics and Mathematical Systems. 2006. Vol. 581. Pp. 283-300. 
Paterson B., Charles A. Community-based Responses to Climate Hazards: Typology and Global Analysis // Climate Change. 2019. Vol. 152. No. 3-4. Pp. 327-343.

Pelling M., Ozerdem A., Barakat S. The Macroeconomic Impact of Disasters // Progress in Development Studies. 2002. Vol. 2. Pp. 283-305.

Richardson K., Steffen W., Liverman D. Climate Change: Global Risks, Challenges and Decisions. Cambridge : Cambridge University Press, 2011.

Rose A. Economic Principles, Issues, and Research Priorities in Hazard Loss Estimation // Modeling Spatial and Economic Impacts of Disasters / ed. by Y. Okuyama, S. Chang. Berlin : Springer-Verlag, 2004. Pp. 13-36.

Tigchelaar M., Battisti D. S., Naylor R. L., Ray D. K. Future Warming Increases Probability of Globally Synchronized Maize Production Shocks // Proceedings National Academy of Sciences of the United States of America, 2018. Vol. 115. Pp. 6644-6649.

Tong S., Confalonieri U., Ebi K., Olsen J. Managing and Mitigating the Health Risks of Climate Change: Calling for Evidence-Informed Policy and Action // Environmental Health Perspectives. 2016. Vol. 124. Pp. 176-179.

\section{References}

Betskov A. V., Tagirov Z. I. Sistemy upravleniya v chrezvychajnoj obstanovke: mezhdunarodnyj opyt i vozmozhnosti ego ispol'zovaniya v Rossii i v gosudarstvah-chlenah Evrazijskogo ekonomicheskogo soyuza [Emergency Management Systems: International Experience and Possibilities of its Use in Russia and in the Member States of the Eurasian Economic Union] // Problemy bezopasnosty i chrezvychaynykh situatsiy. 2017. No. 6. Pp. 3-13.

Kobysheva N. V., Akentieva E. M., Galyuk L. P. Klimaticheskie riski i adaptatsiya k izmeneniyam $\mathrm{i}$ izmenchivosti klimata $\mathrm{v}$ tehnicheskoj sfere [Climate Risks and Adaptation to Climate Change and Variability in the Technical Field]. Saint Petersburg : Kirillitsa Press, 2015.

Osipov V. I. Prirodnye opasnosti i strategicheskie riski v mire i Rossii [Natural Hazards and Strategic Risks in the World and in Russia] // Ekologiya i zhizn'. 2009. No. 11-12. Pp. 5-15.

Porfiriev B. N., Makarova E. A. Ekonomicheskaya otsenka ushcherba ot prirodnyh bedstvij i katastrof [Economic Assessment of Damage From Natural Disasters and Catastrophes] // Byulleten' Rossiyskoy akademii nauk. 2014. Vol. 84(12). Pp. 1059-1072.

Sinyak Yu. V. Vliyanie klimaticheskih riskov na tempy i strukturu razvitiya Rossijskogo TEK v pervoj polovine XXI veka [Influence of Climatic Risks on the Rate and Structure of Development of the Russian Fuel and Energy Complex in the First Half of the XXI Century] // Energeticheskaya politika. 2016. No. 3. Pp. 31-42.

Upravlenie riskami tehnogennyh katastrof i stihijnyh bedstvij [Risk Management of Man-made Catastrophes and Natural Disasters] / ed. by M. I. Faleev. Moscow : FGBU VNII GOChS Press, 2016.

Yakovleva E. N., Yashalova N. N., Ruban D. A., Vasiltsov V. S. Metodicheskie podhody $\mathrm{k}$ otsenke prirodno-klimaticheskih riskov $\mathrm{v}$ tselyah ustojchivogo razvitiya gosudarstva [Methodological Approaches to the Assessment of Natural and Climatic Risks for the Sustainable Development of the State] // Uchenyye zapiski Rossiyskogo gosudarstvennogo gidrometeorologicheskogo universiteta. Section: Ekologiya. 2018. No. 52. Pp. 120-137. 
Ansell C., Baur P. Explaining Trends in Risk Governance: How Problem Definitions Underpin Risk Regimes // Risk, Hazards, \& Crisis in Public Policy. 2018. Vol. 9(4). Pp. 397-430.

Aven T. An Emerging New Risk Analysis Science: Foundations and Implications // Risk Analysis. 2018. Vol. 38(5). Pp. 876-888.

Benegal S. D. The Impact of Unemployment and Economic Risk Perceptions on Attitudes Towards Anthropogenic Climate Change // Journal of Environmental Studies and Sciences. 2018. Vol. 8. Pp. 300-311.

Haddow G. D., Bullock J. A. Introduction to Emergency Management. Amsterdam : Butter-Worth-Heinemann Press, 2005.

Hallegatte S., Przyluski V. The Economics of Natural Disasters: Concepts and Methods. Policy Research Working Paper No. WPS 5507. Washington (DC) : World Bank Press, December, 2010.

Holzheu T., Turner G. The Natural Catastrophe Protection Gap: Measurement, Root Causes and Ways of Addressing Underinsurance for Extreme Events // The Geneva Papers on Risk and Insurance. 2018. Vol. 43(1). Pp. 37-71.

Leng G. Keeping Global Warming Within $1.5^{\circ} \mathrm{C}$ Reduces Future Risk of Yield Loss in the United States: A Probabilistic Modeling Approach // Science of the Total Environment. 2018. Vol. 644. Pp. 52-59.

O’Neill B., Ermoliev Y., Ermolieva T. Endogenous Risks and Learning in Climate Change Decision Analysis // Lecture Notes in Economics and Mathematical Systems. 2006. Vol. 581. Pp. 283-300.

Paterson B., Charles A. Community-based Responses to Climate Hazards: Typology and Global Analysis // Climate Change. 2019. Vol. 152(3-4). Pp. 327-343.

Pelling M., Ozerdem A., Barakat S. The Macroeconomic Impact of Disasters // Progress in Development Studies. 2002. Vol. 2. Pp. 283-305.

Richardson K., Steffen W., Liverman D. Climate Change: Global Risks, Challenges and Decisions. Cambridge : Cambridge University Press, 2011.

Rose A. Economic Principles, Issues, and Research Priorities in Hazard Loss Estimation // Modeling Spatial and Economic Impacts of Disasters / ed. by Y. Okuyama, S. Chang. Berlin : Springer-Verlag, 2004. Pp. 13-36.

Tigchelaar M., Battisti D. S., Naylor R. L., Ray D. K. Future Warming Increases Probability of Globally Synchronized Maize Production Shocks // Proceedings National Academy of Sciences of the United States of America. 2018. Vol. 115. Pp. 6644-6649.

Tong S., Confalonieri U., Ebi K., Olsen J. Managing and Mitigating the Health Risks of Climate Change: Calling for Evidence-Informed Policy and Action // Environmental Health Perspectives. 2016. Vol. 124. Pp. 176-179. 